\title{
Equilibrium isotherm and kinetic studies for the simultaneous removal of phenol and cyanide by use of $S$. odorifera (MTCC 5700) immobilized on coconut shell activated carbon
}

\author{
Neetu Singh $^{1} \cdot$ Chandrajit Balomajumder $^{1}$
}

Received: 15 March 2016/Accepted: 1 September 2016/Published online: 14 September 2016

(C) The Author(s) 2016. This article is published with open access at Springerlink.com

\begin{abstract}
In this study, simultaneous removal of phenol and cyanide by a microorganism S. odorifera (MTCC 5700) immobilized onto coconut shell activated carbon surface (CSAC) was studied in batch reactor from mono and binary component aqueous solution. Activated carbon was derived from coconut shell by chemical activation method. Ferric chloride $\left(\mathrm{Fecl}_{3}\right)$, used as surface modification agents was applied to biomass. Optimum biosorption conditions were obtained as a function of biosorbent dosage, $\mathrm{pH}$, temperature, contact time and initial phenol and cyanide concentration. To define the equilibrium isotherms, experimental data were analyzed by five mono component isotherm and six binary component isotherm models. The higher uptake capacity of phenol and cyanide onto CSAC biosorbent surface was 450.02 and $2.58 \mathrm{mg} / \mathrm{g}$, respectively. Nonlinear regression analysis was used for determining the best fit model on the basis of error functions and also for calculating the parameters involved in kinetic and isotherm models. The kinetic study results revealed that Fractal-like mixed first second order model and Brouser-Weron-Sototlongo models for phenol and cyanide were capable to offer accurate explanation of biosorption kinetic. According to the experimental data results, CSAC with immobilization of bacterium S. odorifera (MTCC 5700) seems to be an alternative and effective biosorbent for the elimination of phenol and cyanide from binary component aqueous solution.
\end{abstract}

Neetu Singh

neeturbs@gmail.com

Chandrajit Balomajumder

chandfch@iitr.ernet.in

1 Department of Chemical Engineering, Indian Institute of Technology, Roorkee, India
Keywords Cyanide - Impregnation · Phenol - Kinetic · Microorganism $\cdot$ Multicomponent modeling

\begin{tabular}{|c|c|}
\hline \multicolumn{2}{|c|}{ Nomenclature } \\
\hline$Q_{\mathrm{o}}$ & Langmuir model constant $(\mathrm{mg} / \mathrm{g})$ \\
\hline & Langmuir model constant \\
\hline$Q_{\mathrm{e}, i}$ & $\begin{array}{l}\text { Amount of } i \text { th component adsorbed per gram of } \\
\text { adsorbent at equilibrium }(\mathrm{mg} / \mathrm{g})\end{array}$ \\
\hline$Q_{\mathrm{o}, i}$ & $\begin{array}{l}\text { Constant in modified Langmuir model for } i \text { th } \\
\text { component }(\mathrm{mg} / \mathrm{g})\end{array}$ \\
\hline$C_{\mathrm{e}, i}$ & $\begin{array}{l}\text { Concentration of } i \text { th component in the binary } \\
\text { mixture at equilibrium }(\mathrm{mg} / \mathrm{L})\end{array}$ \\
\hline$K_{\mathrm{F}}$ & Freundlich model constant $(\mathrm{mg} / \mathrm{g})$ \\
\hline$n$ & Freundlich, Toth model constant \\
\hline$K_{\mathrm{F}, i}$ & Extended Freundlich model constant $(\mathrm{mg} / \mathrm{g})$ \\
\hline$K_{\mathrm{RP}}$ & Redlich-Peterson model constant $(\mathrm{L} / \mathrm{g})$ \\
\hline$a_{\mathrm{RP}}$ & Redlich-Peterson model constant (Lmg) \\
\hline$\beta$ & Redlich-Peterson model constant \\
\hline$\eta_{\mathrm{RP}, i}$ & $\begin{array}{l}\text { Binary component Redlich-Peterson model } \\
\text { constant }(\mathrm{L} / \mathrm{g})\end{array}$ \\
\hline$a_{\mathrm{RP}, i}$ & $\begin{array}{l}\text { Binary component Redlich-Peterson model } \\
\text { constant }(\mathrm{L} / \mathrm{mg})\end{array}$ \\
\hline$\beta_{j}$ & $\begin{array}{l}\text { Binary component Redlich-Peterson model } \\
\text { constant }\end{array}$ \\
\hline$x_{i}, y_{i}, z_{i}$ & Constant in modified Redlich-Peterson model \\
\hline 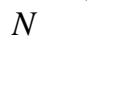 & $\begin{array}{l}\text { Number of observations in the experimental } \\
\text { isotherm }\end{array}$ \\
\hline$P$ & Number of parameter in the regression model \\
\hline$Q_{\mathrm{e}, i}^{\exp }$ & Experimental value of $Q_{\mathrm{e}}(\mathrm{mg} / \mathrm{g})$ \\
\hline$Q_{\mathrm{e}, i}^{\mathrm{cal}}$ & Predicted value of $Q_{\mathrm{e}}(\mathrm{mg} / \mathrm{g})$ \\
\hline$\alpha_{1}$ & $\begin{array}{l}\text { Constant in Fritz-Schlunder isotherm }(\mathrm{mg} / \mathrm{g}) / \\
(\mathrm{mg} / \mathrm{L})^{\beta 1}\end{array}$ \\
\hline$x_{2}$ & Constant in Fritz-Schlunder isotherm $(\mathrm{mg} / \mathrm{L})-\beta 2$ \\
\hline & Constants in Fritz-Schlunder isotherm \\
\hline
\end{tabular}

\section{Nomenclature}

$(\mathrm{mg} / \mathrm{g})$

$b \quad$ Langmuir model constant

$Q_{\mathrm{e}, i} \quad$ Amount of $i$ th component adsorbed per gram of adsorbent at equilibrium $(\mathrm{mg} / \mathrm{g})$ component $(\mathrm{mg} / \mathrm{g})$ mixture at equilibrium $(\mathrm{mg} / \mathrm{L})$

$K_{\mathrm{F}} \quad$ Freundlich model constant $(\mathrm{mg} / \mathrm{g})$

$n \quad$ Freundlich, Toth model constant

$K_{\mathrm{F}, i} \quad$ Extended Freundlich model constant $(\mathrm{mg} / \mathrm{g})$

$K_{\mathrm{RP}} \quad$ Redlich-Peterson model constant $(\mathrm{L} / \mathrm{g})$

$a_{\mathrm{RP}} \quad$ Redlich-Peterson model constant (Lmg)

$\beta \quad$ Redlich-Peterson model constant

$\eta_{\mathrm{RP}, i} \quad$ Binary component Redlich-Peterson model constant $(\mathrm{L} / \mathrm{g})$ constant $(\mathrm{L} / \mathrm{mg})$ constant

$x_{i}, y_{i}, z_{i} \quad$ Constant in modified Redlich-Peterson model isotherm

Number of parameter in the regression model Experimental value of $Q_{\mathrm{e}}(\mathrm{mg} / \mathrm{g})$

Predicted value of $Q_{\mathrm{e}}(\mathrm{mg} / \mathrm{g})$ $(\mathrm{mg} / \mathrm{L})^{\beta 1}$

$\beta_{1} \beta_{2} \quad$ Constants in Fritz-Schlunder isotherm 


\section{Introduction}

Currently, with the rapid increase of industries, water pollution problem has become progressively serious (Doney 2010). Among all pollutants enclosed in industrial wastewater, phenol and cyanide are considered the most hazardous compounds for the environment (Busca et al. 2008; Vedula and Balomajumder 2011). Phenol and cyanide are regularly derived from wastewater generated from synthetic fuel processing, petrochemicals, and steel manufacturing industries comprises high concentrations of phenol (700-6000 mg/L), and cyanide $(10-150 \mathrm{mg} / \mathrm{L})$ (Kim et al. 2008; Liu et al. 1996). Moreover, phenol and cyanide can also increase risks of heart pains, thyroid gland enlargement, breathing disorders, headaches, gastrointestinal disorders, skin and eyes injuries, central nervous system, kidney, liver, lung damage, and even death (ATSDR 2006, 2008). Because of its several harmful effects, the elimination of phenol and cyanide from industrial wastewaters before their release into water bodies is measured to be essential ( $\mathrm{Lu}$ et al. 2012). The maximum tolerance limit for phenol and cyanide in drinking water according to the Minimum Nationals Standards (MINAS) of the Central Pollution Control Board (CPCB) in India and US Environmental Protection Agency (USEPA), is 0.5 and $0.2 \mathrm{mg} / \mathrm{L}$, respectively (Busca et al. 2008; Akcil 2003). Numerous methods have been used for elimination of phenol and cyanide from wastewater comprising biosorption, solvent extraction, electrochemical oxidation, membrane separation, chemical coagulation, and photocatalytic degradation, etc. (Akcil 2003; Dash et al. 2009; Kujawski et al. 2004). Out of these treatment methods, biosorption has been established to be the superior method. It is a well-organized and inexpensive method for elimination of phenol and cyanide (Agarwal et al. 2013; Lin and Juang 2009; Singh et al. 2016). Therefore, numerous biosorbents have been established and widely used for biosorption of phenol and cyanide (Agarwal et al. 2013; Lin and Juang 2009; Singh et al. 2016; Daffalla et al. 2013).

Coconut shell activated carbon is most widely used as biosorbent for the treatment of industrial effluents (Kirubakaran et al. 1991; Su et al. 2003). Furthermore, to enhance the biosorption capacity of biosorbents, surface modification by metal impregnation technique has been employed. Several authors were using metal impregnation technique in the literature for the removal of pollutants due to its high removal efficiency (Deveci et al. 2006; Mondal et al. 2008).

Though, since biosorption is just a process of focussing the toxicants onto the biosorbent surface, the biosorbent will no longer be useful when the active sites available onto surface have been exhausted. The spent biosorbent converts a secondary waste and will essential to be either discarded or regenerated. The use of microorganisms to regenerate the surface of the biosorbent for more removal is known as bioregeneration/bioaccumulation. Studies based on the simultaneous biosorption and bioregeneration/bioaccumulation of biosorbents have been reported by many researchers (Agarwal and Balomajumder 2013; Dash et al. 2008; Silva et al. 2004). As a promising knowledgeS, bioregeneration process defined by which the surface of the biosorbent is being regenerated by the action of microorganisms, thus increasing the removal capacity of biosorbent. The encouraging effects of the simultaneous biosorption and bioaccumulation processes for the treatment of toxic compounds are esteemed in the enhancement of the bioaccumulation rate and an increase in the removal capacity of biosorbents. Some of the bacteria having phenol and cyanide degradability capacity are $S$. odorifera, $R$. erythropolis, $P$. putida, Bacillus, A. chroococcum 446, etc. (Agarwal and Balomajumder 2012; Dash et al. 2008, 2009a, 2014; Prieto et al. 2002).

However, the main intention of this current investigation are, (1) to develop an environmental friendly and cost effective biosorbent from coconut shell, (2) to determine the optimum value of experimental parameters affecting the process viz. biosorbent dose, $\mathrm{pH}$, contact time, temperature and initial concentration of phenol and cyanide for simultaneous elimination of phenol and cyanide by the use of immobilized culture of S. odorifera (MTCC 5700) onto the surface of CSAC, (3) to determine the parameters of mono component and binary component adsorption equilibrium isotherms models, and (4) to determine the kinetics of process and find out the best fit kinetic models.

\section{Materials and methods}

\section{Preparation of biosorbent}

Coconut shell was collected from local market of Roorkee, India. Coconut shell was first washed with double distilled water to eliminate the impurities like dirt and dried at $60{ }^{\circ} \mathrm{C}$ temperature in an oven for $12 \mathrm{~h}$. After drying, coconut shell was crushed in a high-speed rotary mill into 2-3 mm size of pieces and stored for additional processing in a muffle furnace (Amudaa et al. 2007; Sodeinde 2012). To prepare the coconut shell activated carbon using chemical activation method, the dried coconut shell was soaked with $2 \mathrm{~N} \mathrm{H}_{2} \mathrm{SO}_{4}$ in a muffle furnace at temperature $300{ }^{\circ} \mathrm{C}$ for $12 \mathrm{~h}$ in $1: 3$ ratio of solid to liquid to enhance the surface area. The coconut shell activated carbon was washed with Millipore water to eliminate residual 
chemicals and then the sample was dried at $110^{\circ} \mathrm{C}$ temperature for $24 \mathrm{~h}$. The surface modification of CSAC was achieved by impregnation with ferric chloride $\left(\mathrm{Fecl}_{3}\right)$. The impregnation was carried out at $70{ }^{\circ} \mathrm{C}$ in an oven until the complete evaporation of water was detected, and then the CSAC was dried at $110^{\circ} \mathrm{C}$ for $24 \mathrm{~h}$ (Mondal et al. 2008). The dried sample was washed with Millipore water until the washing liquid was free from iron, and then dried to constant weight and used as impregnated activated carbon for further studies.

\section{Chemicals and preparation of adsorbate solutions}

All analytical reagent grade chemicals were used without additional purification in this study and supplied by Himedia Laboratories Pvt. Mumbai, India. Double distilled, deionized water (Milli-Q Millipore $18.2 \mathrm{M} / \mathrm{cm}$ conductivity) was used for preparation of all solutions. A stock solution of phenol and cyanide were prepared by dissolving measured amount of phenol and sodium cyanide in $1 \mathrm{~L}$ of deionized water with varying concentrations of phenol 100-1000 mg/L and cyanide 10-100 mg/L.

\section{Acclimatization and immobilization of microorganism}

The strain S. odorifera (MTCC 5700) was isolated from coke industry wastewater in the laboratory, by Agarwal and Balomajumder (2012). The composition of growth mineral media was $\mathrm{Na}_{2} \mathrm{HPO}_{4}, \mathrm{KH}_{2} \mathrm{PO}_{4}, \mathrm{NaCl}, \mathrm{NH}_{4} \mathrm{Cl}, \mathrm{MgSO}_{4}$ $7 \mathrm{H}_{2} \mathrm{O}$ and glucose in distilled water. All inoculations were achieved in aseptic environments in laminar air flow unit (Rescholar Equipment, INDIA). Acclimatization process was accompanied for familiarization of strain to phenol and cyanide environment. The $\mathrm{pH}$ was pre adjusted to 8 and the growth medium sterilized using autoclave at $121{ }^{\circ} \mathrm{C}$ for 15 min. To acclimatize the strain, $2 \%$ glucose was supplemented for suitable growth of the strain in growth medium comprising substrate phenol and cyanide. Strain was acclimatized by revealing them to the toxic solution in a sequence of $250 \mathrm{~mL}$ conical flasks with working volume of $100 \mathrm{~mL}$. Glucose concentration was reduced regularly with increasing concentration of the phenol and cyanide into the growth medium for a period of 30 days. After acclimatization, the medium was solidified with $2 \%$ of pure agar (Merck). The flasks were incubated at $30{ }^{\circ} \mathrm{C}$ in an incubator cum orbital shaker (Metrex, MO-250, India) with shaking speed $120 \mathrm{rpm}$ in the dark to avoid photodestruction of phenol and cyanide. The cultures were streaking on agar plates added with phenol and cyanide and incubated at $30{ }^{\circ} \mathrm{C}$ for $48 \mathrm{~h}$. The growth curve of microorganism S. odorifera (MTCC 5700) was obtained by centrifuge the cultivated cells of $S$. odorifera (MTCC 5700) at $8000 \mathrm{rpm}$ for $15 \mathrm{~min}$. Thereafter, the pellet was formed at the bottom of the centrifuge tube. The pellet was washed with double distilled water and observed its optical density (O.D.) at $600 \mathrm{~nm}$ at time interval of $2 \mathrm{~h}$ in UV-Vis spectrophotometer (Hach, USA). Maximum growth of strain was obtained at $30 \mathrm{~h}$, and continues till $42 \mathrm{~h}$, further than the strain starts to decline.

\section{Batch experimental procedure}

The biosorption of phenol and cyanide onto CSAC was carried out by batch process in an orbital shaker. The batch biosorption experiments were accomplished in $250 \mathrm{~mL}$ glass flasks with $100 \mathrm{~mL}$ of phenol and cyanide solutions of known concentration. The solution was continuously stirred at fixed temperature for an assured time to attain the equilibrium. The time after which no change in percentage removal or concentration is detected, will be the equilibrium time. After attaining an equilibrium process, the biosorbent gets separated from samples using Whatman filter No. 41 and microorganism separated by centrifuge at $10,000 \mathrm{rpm}$. Thereafter, concentration of phenol and cyanide was determined using UV-Vis spectrophotometer (APHA 1998). To examine the influence of biosorption parameters on biosorption of phenol and cyanide onto CSAC, such as biosorbent dosage (5-60 g/L), pH (4-12), initial phenol concentration $(100-1000 \mathrm{mg} / \mathrm{L})$, initial cyanide concentration $(10-100 \mathrm{mg} / \mathrm{L})$, contact time $(2-50 \mathrm{~h})$ and temperature $\left(20-40{ }^{\circ} \mathrm{C}\right)$, were calculated in a batch approach.

The total amount of phenol and cyanide adsorbed per unit mass of the biosorbent at equilibrium $\left(Q_{\mathrm{e}}\right)$ and at time $t$ $\left(Q_{t}\right)$ was designed using the following equation,

$$
\begin{aligned}
& Q_{t}=\left(C_{\mathrm{i}}-C_{t}\right) V / M \\
& Q_{\mathrm{e}}=\left(C_{\mathrm{i}}-C_{\mathrm{e}}\right) V / M
\end{aligned}
$$

The percent removal of phenol and cyanide was calculated as follows:

Percentage removal $=\left(\left(C_{\mathrm{i}}-C_{\mathrm{f}}\right) / C_{\mathrm{i}}\right) * 100$

where:

$Q_{\mathrm{e}}$ is the amount of phenol and cyanide adsorbed on to the per unit mass of biosorbent at equilibrium $(\mathrm{mg} / \mathrm{g}), Q_{t}$ is the uptake of phenol and cyanide at time $t(\mathrm{mg} / \mathrm{g}), C_{\mathrm{f}}$ is the final concentration of phenol and cyanide $(\mathrm{mg} / \mathrm{L}), C_{t}$ is the liquid phase concentration of phenol and cyanide at time $t(\mathrm{~h}), C_{\mathrm{i}}$ is the initial pollutant concentration $(\mathrm{mg} / \mathrm{L}), C_{\mathrm{e}}$ is the concentration of adsorbate at equilibrium $(\mathrm{mg} / \mathrm{L}), V$ is the volume of the solution (L), $M$ is the weight of the biosorbent $(\mathrm{g})$.

Equilibrium isotherm was achieved by changing the initial concentration of phenol and cyanide solution 100-1000 and 10-100 mg/L, respectively. Kinetic studies 
were accomplished by changing the phenol and cyanide concentration and samples were collected at several time intervals till the equilibrium reached.

\section{Equilibrium isotherm modeling}

Adsorption equilibrium isotherms are defining the equilibrium interactions between the adsorbed ions in the aqueous solution at a specified temperature. To relate the isotherm equilibrium data, five monocomponent isotherm models and six binary component isotherm models are designated from the literature. Monocomponent isotherm models, such as Langmuir, Freundlich, Redlich-Peterson, Toth and Fritz-Schlunder, and binary component isotherm, such as non-modified Langmuir, modified Langmuir, extended Langmuir, extended Freundlich, non-modified RedlichPeterson and modified Redlich-Peterson models were used.

The Langmuir model recommends a monolayer uptake of the adsorbate onto homogeneous surface of biosorbent, having equal adsorption energies for all available binding sites without any collaboration between the biosorbent (Sawalha et al. 2006). The nonlinear form of the Langmuir isotherm model is represented by the subsequent equation:

$Q_{\mathrm{eq}}=\left(Q_{0} b C_{\mathrm{e}}\right) /\left(1+b C_{\mathrm{e}}\right)$

The Langmuir model parameters can be used to calculate the attraction between the biosorbent and adsorbate using dimensionless separation factor $\left(R_{\mathrm{L}}\right) . R_{\mathrm{L}}$ is designed by the following equation:

$R_{\mathrm{L}}=1 /\left(1+b C_{0}\right)$

The value of $R_{\mathrm{L}}$ shows the nature of the isotherm to be either favorable $\left(0<R_{\mathrm{L}}<1\right)$, unfavorable $\left(R_{\mathrm{L}}>1\right)$, linear $\left(R_{\mathrm{L}}=1\right)$, or irreversible $\left(R_{\mathrm{L}}=0\right)$.

In Freundlich isotherm model, $K_{\mathrm{F}}$ is the measurement of the biosorption capacity and $n$ is the measurement of the intensity of biosorption (Sawalha et al. 2006). The nonlinearized form of Freundlich isotherm equation is shown by the following equation:

$Q_{\mathrm{eq}}=K_{\mathrm{F}} C_{\mathrm{e}}^{1 / n}$

Redlich-Peterson model combines the features of the Langmuir and Freundlich isotherm models. A nonlinear form of Redlich-Peterson model is given below:

$Q_{\mathrm{eq}}=K_{\mathrm{RP}} \cdot C_{\mathrm{eq}} / 1+a_{\mathrm{RP}} \cdot C_{\mathrm{eq}}^{\beta}$

where $K_{\mathrm{RP}}$ and $a_{\mathrm{RP}}$ are the Redlich-Peterson isotherm model constants and $\beta$ is the exponent of Redlich-Peterson isotherm, which lies between 0 and 1 (Carvalho et al. 2007).

Toth and Fritz-Schlunder models are not common in use to define adsorption of organic compounds onto CSAC.
Toth model and Fritz-Schlunder model equation are given below:

Toth model:

$Q_{\mathrm{eq}}=q_{\mathrm{to}} \cdot C_{\mathrm{eq}} /\left(a+C_{\mathrm{eq}}^{n}\right)^{1 / n}$

Fritz-Schlunder:

$Q_{\mathrm{eq}}=\alpha_{1} \cdot C_{\mathrm{eq}}^{\beta_{1}} / 1+\alpha_{2} C_{\mathrm{eq}}^{\beta_{2}}$

The Marquardt's percent standard deviation (MPSD) error function was used to correlate the experimental and calculated values for isotherm and kinetic models are given below:

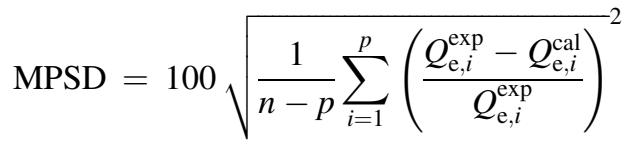

The solution containing binary components has a complicated biosorption mechanism with competition between components and biosorbents sites. The isotherm model Eqs. (11-17) given below have been used to evaluate binary component biosorption behavior (Aksu and Akpinar 2008; Panagou and Kodogiannis 2009).

Non-modified Langmuir:

$Q_{\mathrm{e}, i}=\left(Q_{0, i} b_{i} C_{\mathrm{e}, i}\right) /\left(1+\sum_{j=1}^{N} b_{j}\left(C_{\mathrm{e}, j} / n_{j}\right)\right)$

Modified Langmuir:

$Q_{\mathrm{e}, i}=\left(Q_{0, i} b_{i} C_{\mathrm{e}, i} / n_{i}\right) /\left(1+\sum_{j=1}^{N} b_{j}\left(C_{\mathrm{e}, j} / n_{j}\right)\right)$

Extended Langmuir:

$Q_{\mathrm{e}, i}=\left(Q_{0, i} b_{i} C_{\mathrm{e}, i}\right) /\left(1+\sum_{j=1}^{N} b_{j} C_{\mathrm{e}, j}\right)$

Extended Freundlich:

$Q_{\mathrm{e}, i}=\left(K_{\mathrm{F}, i} C_{\mathrm{e}, i}^{1 / n i+x i}\right) /\left(C_{\mathrm{e}, i}^{x i}+y 1 C_{\mathrm{e}, j}^{z, i}\right)$

$Q_{\mathrm{e}, j}=\left(K_{\mathrm{F}, j} C_{\mathrm{e}, j}^{1 / n j+x j}\right) /\left(C_{\mathrm{e}, j}^{x j}+y 2 C_{\mathrm{e}, i}^{z, j}\right)$

Non-modified Redlich-Peterson model

$Q_{\mathrm{e}, i}=K_{\mathrm{RP}_{i}} \cdot C_{\mathrm{eq}_{i}} / 1+\sum_{j=1}^{N} a_{\mathrm{RP}_{j}}\left(C_{\mathrm{eq}_{j}}\right)^{\beta_{j}}$

Modified Redlich-Peterson model

$Q_{\mathrm{e}, i}=K_{\mathrm{RP}_{i}} \cdot\left(\frac{C_{\mathrm{eq}_{i}}}{\eta_{\mathrm{RP}, i}}\right) / 1+\sum_{j=1}^{N} a_{\mathrm{RP}_{j}}\left(\frac{C_{\mathrm{eq}, i}}{\eta_{\mathrm{RP}, i}}\right)^{\beta_{j}}$

The ratio of capacities of adsorption process $\left(Q_{q, i}\right)$ is defined by given formula:

$Q_{q, i}=Q_{i, \text { multi }} / Q_{i, \text { single }}$

where $Q_{i \text { multi }}$ is the binary component adsorption capacity for component $i$ in the binary solution and $Q_{i \text {,single }}$ is the 
monocomponent adsorption capacity of the same pollutant at the similar operating conditions of the binary solution. Parameter $Q_{q, i}$ permits to relate the binary component biosorbent performance with the results acquired in monocomponent systems using the same operating environments.

Literature designates that (Reynel-Avila et al. 2011) (1) if $Q_{q, i}>1$, the presence of other component in binary component systems increases the biosorption of component $i$ (i.e., synergistic adsorption), (2) if $Q_{q, i}=1$, there is no effect on the binary component biosorption of component $i$, and (3) if $Q_{q, i}<1$, the biosorption of component $i$, is decrease by the presence of other component in the binary component aqueous solution (i.e., antagonistic adsorption).

\section{Kinetic modeling}

Adsorption kinetic modeling was established to recognize the mechanism of phenol and cyanide biosorption on to biosorbents. Kinetics studies distribute the information about the possible mechanism of biosorption that comprises the diffusion (external, intraparticle and bulk) and chemical reactions. In general, the adsorbate transport follows in the few steps.

(1) The transport of adsorbate in the bulk solution, (2) the external diffusion from the bulk solution to the exterior surface of the biosorbent, (3) the transport of the adsorbate through the boundary layer (4) the transfer of adsorbate in the pores of the biosorbent and lastly uptake of adsorbate molecules by the active sites, and (5) the biosorption and desorption of adsorbate (Michalak et al. 2013). To evaluate the dynamic biosorption behavior of phenol and cyanide onto $S$. odorifera MTCC 5700 immobilized on CSAC, fourteen kinetic models were used in this study assuming that concentrations of adsorbate on the adsorbent surface are equal to the measured concentrations. Among them, fractional power model, pseudo first order and pseudo second order are the empirical models, though their major shortcoming is that they may only define the adsorption kinetics at some situations (Haerifar and Azizian 2013). Elovich kinetic model, fractional power, Ritchie second order and exponential kinetic models are two the parametric empirical models to analyze the kinetic data. Other three parametric kinetic models, for example, Avrami, modified pseudo second order, and mixed first, second order equations have been suggested for adsorption kinetics at the solid/solution interface.

Equations (19)-(32) describes various kinetic models used in this study.

Fractional power model:

$q_{t}=k_{\mathrm{fp}} t^{v}$

Where $k_{\mathrm{fp}}$ is the fractional power model rate constant $\left(\mathrm{mg} \mathrm{g}^{-1} \mathrm{~h}^{-1}\right), v$ is the adjustment parameter.
Pseudo first order:

$q_{t}=q_{\mathrm{e}}\left(1-\exp \left(-k_{1} t\right)\right)$

where $k_{1}$ is the pseudo first order adsorption rate constant $\left(\mathrm{h}^{-1}\right)$.

The pseudo second order kinetics model is expressed as:

Pseudo second order:

$q_{t}=k_{2} q_{\mathrm{e}}^{2} t /\left(1+q_{\mathrm{e}} k_{2} t\right)$

where $k_{2}$ is the pseudo second order adsorption rate constant $\left(\mathrm{g} \mathrm{mg}^{-1} \mathrm{~h}^{-1}\right)$.

Elovich model:

$q_{t}=\left(\frac{2.3}{b_{\mathrm{el}}}\right) \times \log \left(\frac{t+1}{a_{\mathrm{el}} b_{\mathrm{el}}}\right)-\left(\frac{2.3}{b_{\mathrm{el}}}\right) \times \log \left(\frac{1}{a_{\mathrm{el}} b_{\mathrm{el}}}\right)$

where, $a_{\mathrm{el}}$ Elovich coefficient representing the initial adsorption rate $\left(\mathrm{g} \mathrm{mg}^{-1} \mathrm{~h}^{-1}\right), b_{\mathrm{el}}$ Elovich coefficient representing desorption constant $\left(\mathrm{g} \mathrm{mg}^{-1}\right)$.

Avrami model:

$q_{t}=q e\left(1-\exp \left[-\left(k_{\mathrm{av}} t\right)\right]^{n_{a v}}\right)$

where, $k_{\mathrm{av}}$ the Avrami kinetic rate coefficient $\left(\mathrm{h}^{-1}\right), n_{\mathrm{av}}$ the constant corresponding to the mechanism of adsorption.

Modified second order model:

$q_{t}=q_{\mathrm{e}}\left[1-\left(\frac{1}{b_{1 \mathrm{~m}}+k_{1 \mathrm{~m}} t}\right)\right]$

where, $k_{1 \mathrm{~m}}$ is the modified second order rate coefficient $\left(\mathrm{h}^{-1}\right), b_{1 \mathrm{~m}}$ constant.

Ritchie second order model:

$q_{t}=q_{e}\left[1-\left(\frac{1}{1+k_{1 R} t}\right)\right]$

where, $k_{1 \mathrm{R}}$ is the Ritchie second order rate coefficient $\left(\mathrm{h}^{-1}\right)$

Exponential kinetic model:

$q_{t}=q_{\mathrm{e}}\left(\ln \left[2.72-1.72 \exp \left(-k_{\mathrm{ex}} t\right)\right]\right)$

where, $k_{\mathrm{ex}}$ is the exponential rate coefficient $(\mathrm{mg} / \mathrm{g})$

Mixed first, second order model:

$q_{t}=q_{\mathrm{e}}\left[\frac{1-\exp \left(-k_{\mathrm{m}} t\right)}{1-f_{2} \exp \left(-k_{\mathrm{m}} t\right)}\right]$

where, $k_{\mathrm{m}}$ is the mixed first, second order rate coefficient $\left(\mathrm{h}^{-1}\right), f_{2}$ is the involvement of pseudo second order model.

Fractal-like mixed first, second order model:

$q_{t}=q_{\mathrm{e}}\left[\frac{1-\exp \left(-k_{\mathrm{fm}} t^{a}\right)}{1-f_{\mathrm{eq}} \exp \left(-k_{\mathrm{fm}} t^{a}\right)}\right]$

where, $k_{\mathrm{fm}}$ is the Fractal-like mixed first, second order rate coefficient $\left(\mathrm{h}^{-1}\right)^{\alpha}, t^{\alpha}$ is the Fractal time.

Fractal-like first order model:

$q_{t}=q_{\mathrm{e}}\left(1-\exp \left(k_{\mathrm{ff}} t^{a}\right)\right)$ 
where, $k_{\mathrm{ff}}$ is the Fractal-like pseudo first order kinetic rate coefficient $\left(\mathrm{h}^{-1}\right)$

Fractal-like second order model:

$q_{t}=k_{\mathrm{fs}} q_{\mathrm{e}}^{2} t^{a} /\left(1+q_{\mathrm{e}} k_{\mathrm{fs}} t^{a}\right)$

where, $k_{\mathrm{fs}}$ is the Fractal-like pseudo second order kinetic rate coefficient $\left(\mathrm{h}^{-1}\right)$.

Fractal-like exponential model:

$q_{t}=q_{\mathrm{e}}\left(\ln \left[2.72-1.72 \exp \left(-k_{\mathrm{fex}} t^{a}\right)\right]\right)$

where, $k_{\text {fex }}$ is the Fractal-like exponential rate coefficient $\left(\mathrm{h}^{-1}\right)$

Brouser-Weron-Sototlongo model:

$q_{t}=q_{\mathrm{e}}\left[1-\left(1+\left(n_{\mathrm{bws}}-1\right)\left(\frac{t}{t_{\mathrm{bws}, a}}\right)^{a}\right)^{-1 /\left(n_{\mathrm{bws}}-1\right)}\right]$

where, $t_{\mathrm{bws}, \alpha}$ the time required for adsorbing half the maximum amount, $n_{\text {bws }}$ is the fractional reaction order.

\section{Results and discussion}

\section{Characterization of biosorbent}

SEM micrograph of CSAC after impregnation, after immobilization and after simultaneous biosorption and bioaccumulation, are specified in Figs. 1a and 2a. It is seen that the surfaces of the surface modified CSAC are full of voids as shown in Fig. 1a. The surface morphology of CSAC was reformed from smooth to rough and less porous

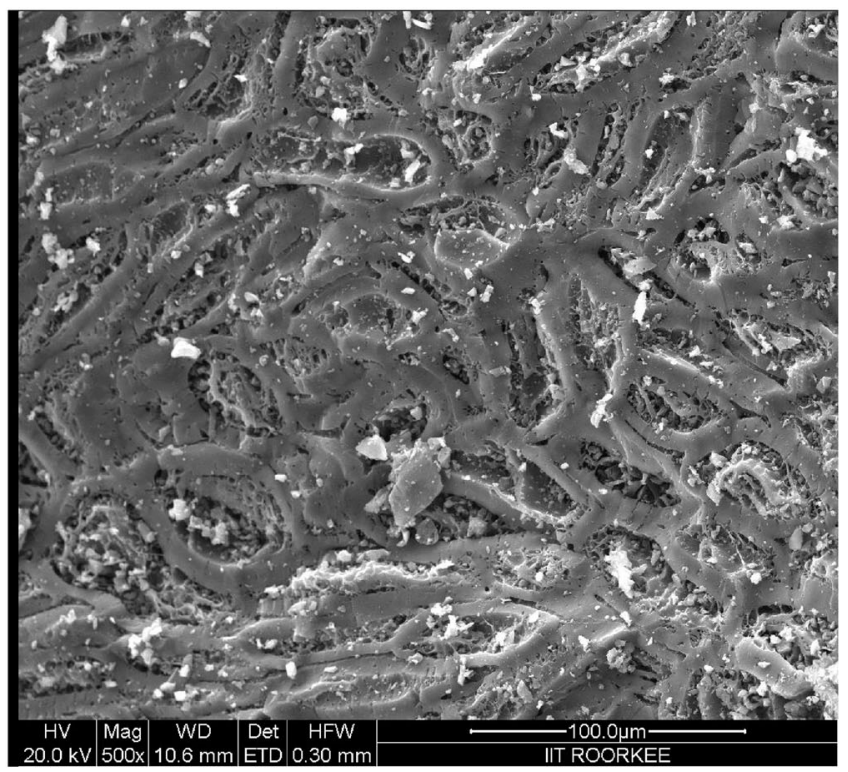

(a) after simultaneous biosorption and bioaccumulation of phenol and cyanide (Agarwal et al. 2013). Total pore volume and surface area (BET) of CSAC biomass was calculated by a surface area analyzer ASAP 2010 Micrometrics, USA. Before immobilization of S. odorifera (MTCC 5700) onto CSAC has a high surface area $\left(81.82 \mathrm{~m}^{2} / \mathrm{g}\right)$, which approves that it is an appropriate biosorbent for the simultaneous elimination of phenol and cyanide. The elemental composition of CSAC was acquired by EDX study. Figures $1 b$ and $2 b$ demonstrate the elemental structure of the biosorbents, after impregnation and after simultaneous biosorption and bioaccumulation, respectively (Table 1). It is apparent from Fig. $1 \mathrm{~b}$ that $1.43 \mathrm{wt} \%$ of iron present on the surface of the biosorbent, indicates surface modification through iron impregnation. From Fig. 2b, it is observed that the clear peaks of elements, such as $\mathrm{C}$, and $\mathrm{O}$ and also minor peaks, such as $\mathrm{Fe}, \mathrm{Na}, \mathrm{k}$ and $\mathrm{N}$, were observed. The elemental composition of $\mathrm{C}, \mathrm{O}, \mathrm{Fe}$ and $\mathrm{k}$, before simultaneous biosorption and bioaccumulation of phenol and cyanide were different from after biosorption Figs. $1 b$ and $2 b$ and indicate uptake of phenol and cyanide.

\section{Effect of pH}

The influence of $\mathrm{pH}$ on the biosorption of phenol and cyanide was studied within the $\mathrm{pH}$ range 4-12 and the results are characterized in Fig. 3a. The $\mathrm{pH}$ interrupts the degree of ionization of the adsorbate throughout the reaction (Moussavi and Khosravi 2010; Srihari and Das 2008). It is observed from the Fig. $3 \mathrm{a}$ that the biosorption of phenol is found constant till $\mathrm{pH} 8$ and then declined,

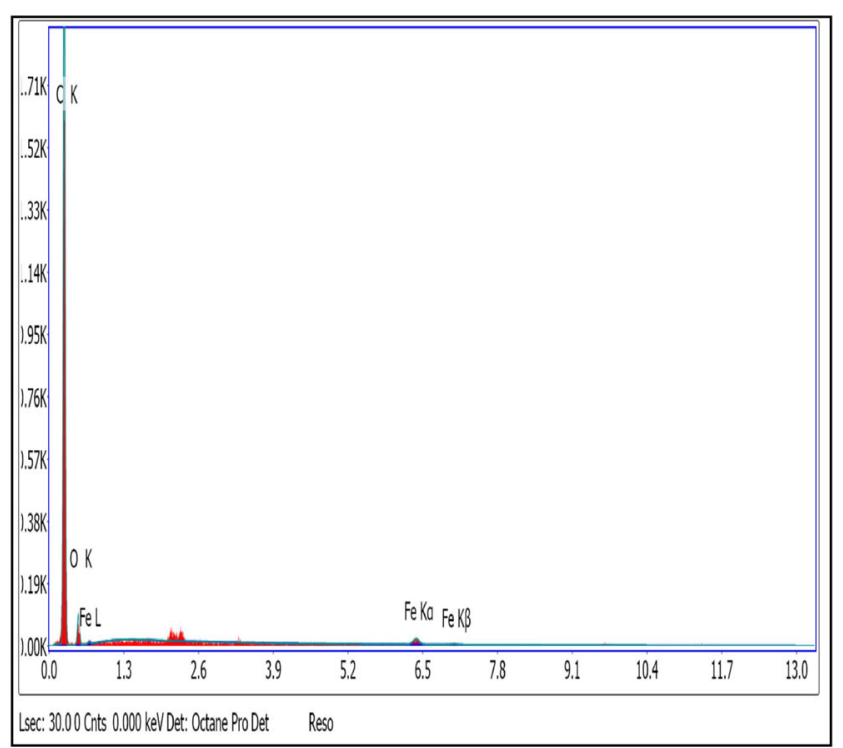

(b)

Fig. 1 a SEM image of CSAC after impregnation, b EDX of CSAC after impregnation 


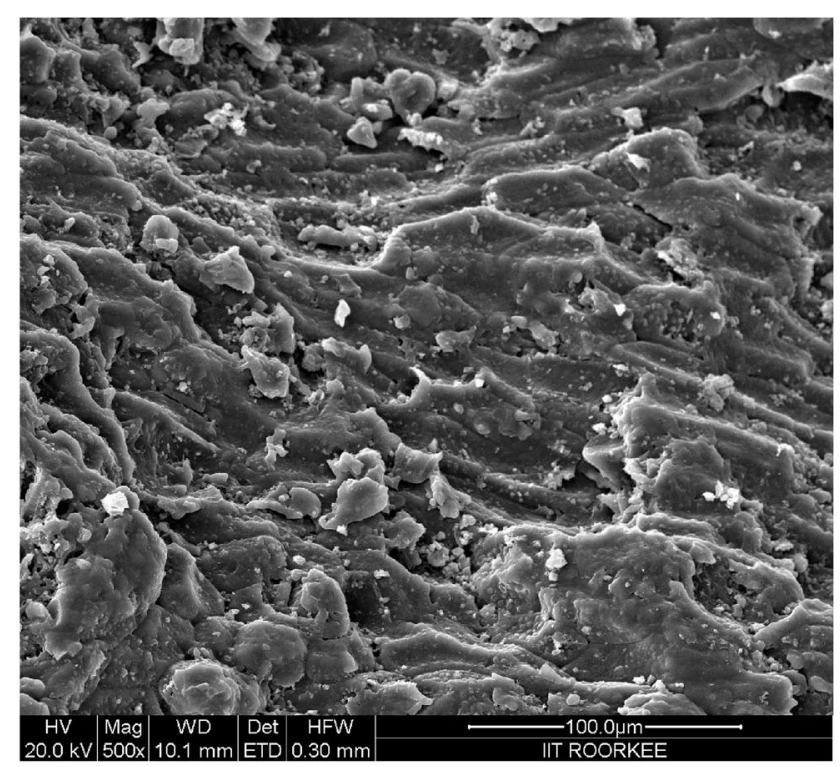

(a)

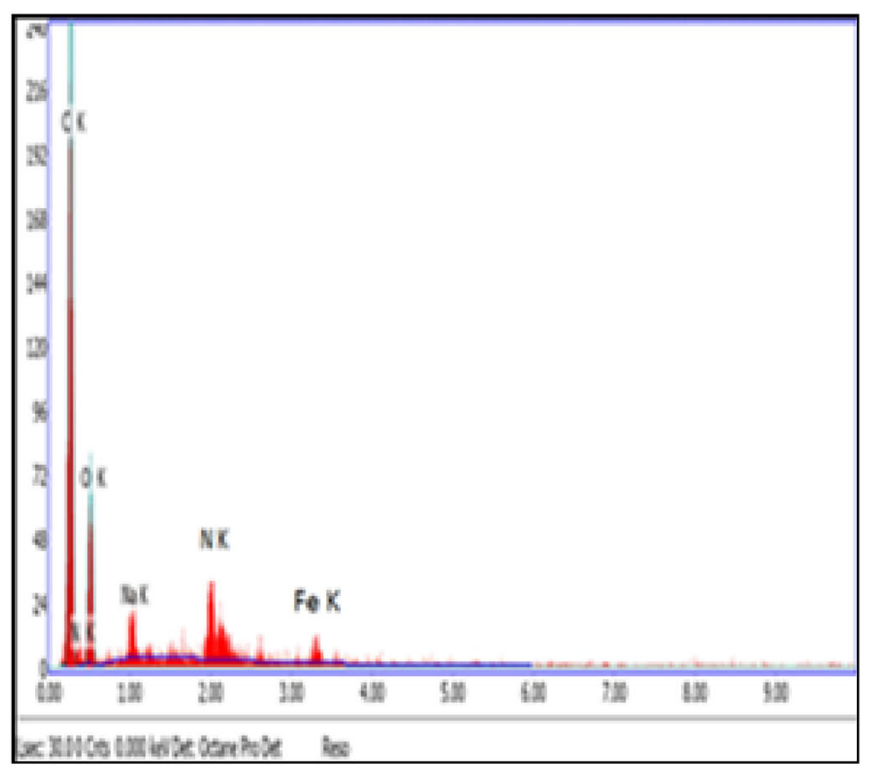

(b)

Fig. 2 a SEM image of CSAC after simultaneous biosorption and bioaccumulation, b EDX of CSAC after simultaneous biosorption and bioaccumulation

Table 1 Surface properties of coconut shell activated carbon (CSAC)

\begin{tabular}{lllll}
\hline & & $\begin{array}{l}\text { BET surface } \\
\text { area }\left(\mathrm{m}^{2} / \mathrm{g}\right)\end{array}$ & $\begin{array}{l}\text { Monolayer } \\
\text { volume }\left(\mathrm{cm}^{2} / \mathrm{g}\right)\end{array}$ & $\begin{array}{l}\text { Total pore } \\
\text { volume }\left(\mathrm{m}^{3} / \mathrm{g}\right)\end{array}$ \\
\hline 1. & Raw CSAC & 67.85 & 11.76 & 0.0086 \\
2. & Before immobilization with S. odorifera & 81.82 & 15.56 & 0.011 \\
3. & After immobilization with S. odorifera & 56.98 & 3.87 & 0.010 \\
4. & After simultaneous biosorption and & 9.99 & 0.098 & 0.008 \\
& $\quad$ bioaccumulation of phenol and cyanide & & & \\
\hline
\end{tabular}

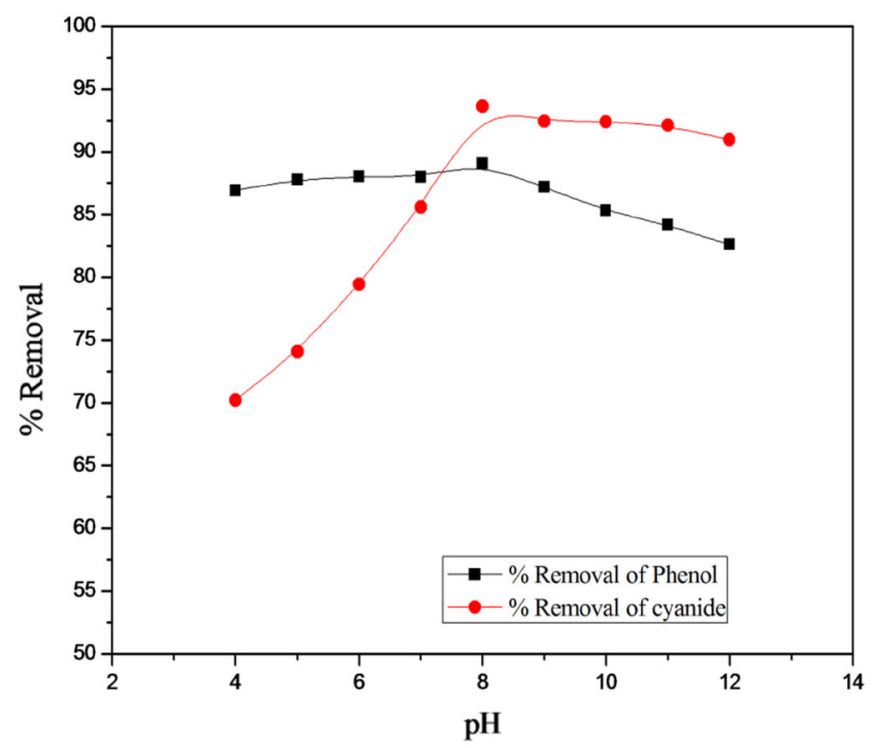

(a)

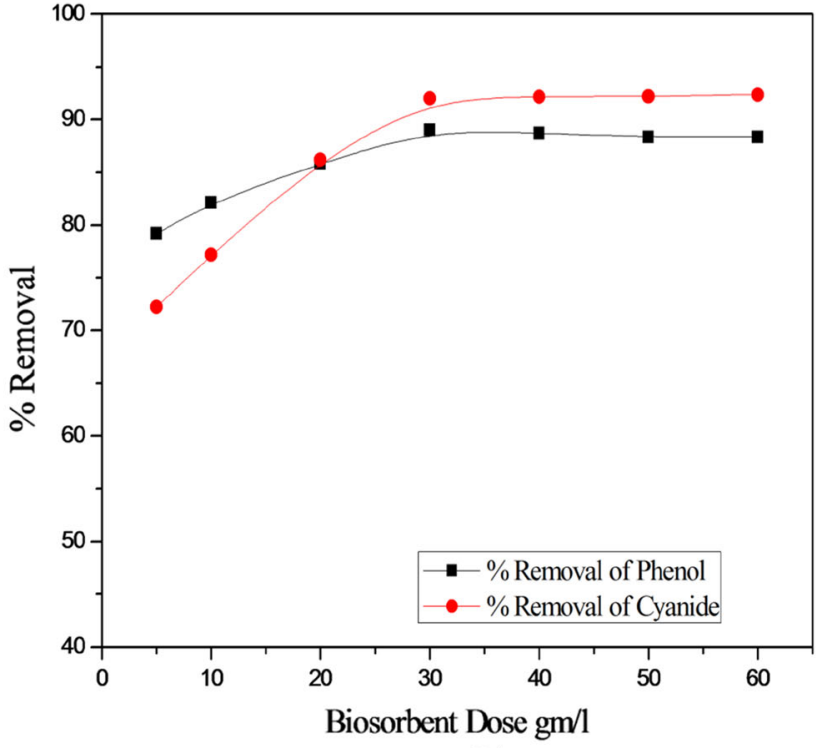

(b)

Fig. 3 a Effect of $\mathrm{pH}$ on \% removal of phenol and cyanide. b Effect of dose on \% removal of phenol and cyanide 
whereas biosorption of the cyanide is found to be increased initially from $\mathrm{pH} 4-8$ and after $\mathrm{pH} 8$ it become constant (Dash et al. 2009b). The maximum biosorption of phenol and cyanide was observed at $\mathrm{pH} 8$ as 89.06 and $93.62 \%$, respectively (Moussavi and Khosravi 2010; Kilic et al. 2011). This may be owing to the variance in the concentrations of $\mathrm{OH}^{-}$and $\mathrm{H}^{+}$in the aqueous solutions. The $\mathrm{H}^{+}$ ions at low $\mathrm{pH}$ atmospheres can deactivate negative sites, decrease the hindrance to distributions of pollutants ions, and therefore increase the probabilities of their biosorption. High $\mathrm{pH}$ atmospheres lead to more concentration of $\mathrm{OH}^{-}$, which can raise the interference to the diffusions of ions, and thus decrease the probabilities of biosorption (Mukherjee et al. 2007; Stavropoulos et al. 2015). The reduction of phenol biosorption at high $\mathrm{pH}$ was due to the electrostatic repulsions between the negative charge onto biosorbent surface and phenol anions in the solution. The major increase in the adsorption of cyanide was found above $\mathrm{pH} 7$ in $\mathrm{NaCN}$ solution. This is due to the fact that cyanide is hydrolyzed in solution to form $\mathrm{HCN}$. The pKa value of hydrocyanic acid is 9.4. So, at $\mathrm{pH}>9.4$, HCN dissociates to $\mathrm{CN}^{-}$ions, whereas at $\mathrm{pH}<9.4$ cyanide occurs in HCN (Stavropoulos et al. 2015; Dash et al. 2009). Then, $\mathrm{CN}^{-}$is a nucleophilic ion and when it comes in contact with the negatively charged biosorbent, it fixes with the anionic functional groups available on the biosorbent surface, and thus increases adsorption. Mostly, researches detected higher biosorption of cyanide at $\mathrm{pH}$ values $8-11$ (Stavropoulos et al. 2015).

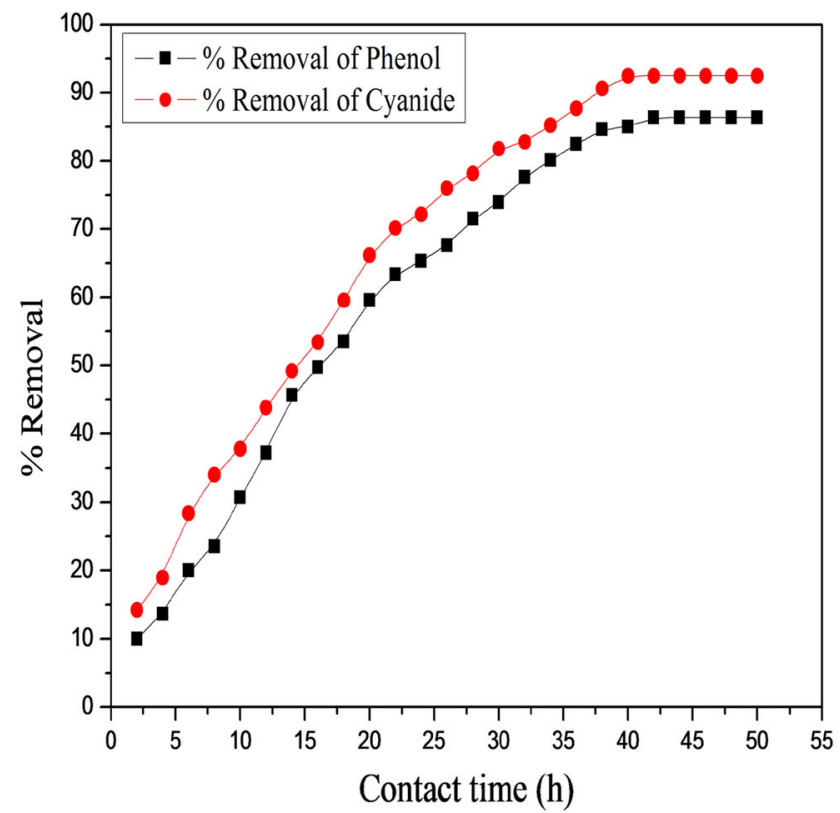

(a)

\section{Effect of biosorbent dose}

The effect of biosorbent dosage on the biosorption of phenol and cyanide was determined within the range of biosorbent dose 5-60 g/L and the results are characterized in Fig. 3b. It is identified that the rise in biosorbent concentration caused in an increase in percent biosorption of phenol and cyanide due to the more availability of the surface area or transferable active sites, but reduced the biosorption due to the incomplete accumulation or overlapping of biosorbent, which outcomes in a reduction in active surface area for the biosorption. It can be understood from Fig. $3 b$ that removal efficiency, increased with increasing biosorbent dose for both phenol and cyanide, but after a definite dosage, the removal efficiency was not increased considerably (Mondal et al. 2008). Thus, the optimum amounts of CSAC dose for additional biosorption experiments were designated as $30 \mathrm{~g} / \mathrm{L}$ for both phenol and cyanide.

\section{Effect of contact time}

The biosorption of phenol and cyanide onto CSAC was carried out at varying contact time $(2-50 \mathrm{~h})$. It is clear from Fig. 4a that the biosorption of phenol and cyanide was fast at the initial stage and equilibrium was attained in $42 \mathrm{~h}$ for phenol and $40 \mathrm{~h}$ for cyanide, where $86.34 \%$ phenol and $92.50 \%$ cyanide was adsorbed. After equilibrium, no significant enhancement was observed in the biosorption

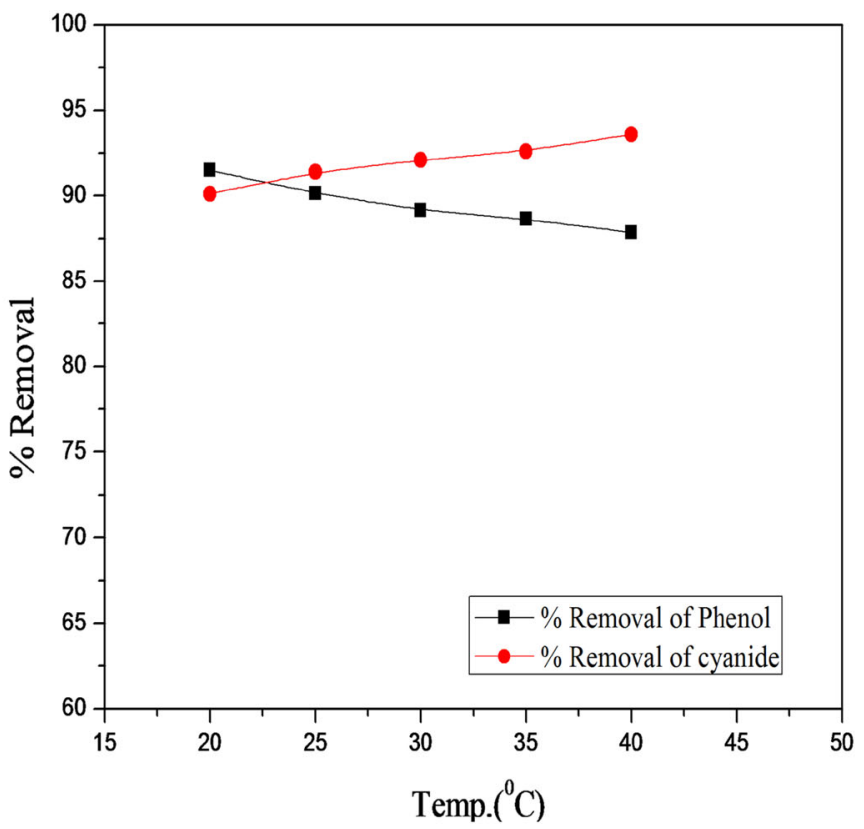

(b)

Fig. 4 a Effect of contact time on \% removal of phenol and cyanide. b Effect of temperature on \% removal of phenol and cyanide 
process. The fast biosorption of phenol and cyanide at the beginning may be owing to the obtainability of huge number of active vacant surface sites on the CSAC surface. Therefore, the molecules of phenol and cyanide were accumulate onto the surface of CSAC, and as a result, the residual vacant sites were problematic to be occupied owing to the establishment of repulsive forces between phenol and cyanide molecules (on biosorbent surface and in the aqueous phase) as well as fewer number of available active vacant sites (Kumar et al. 2011; Ren et al. 2007).

\section{Effect of temperature}

The effect of temperature for the biosorption of phenol and cyanide onto CSAC is shown in Fig. 4b. It was detected that the biosorption of phenol decreased from 91.5 to $87.86 \%$ and biosorption of cyanide increased from 90.12 to $93.6 \%$ with an increase in temperature from 20 to $40{ }^{\circ} \mathrm{C}$, respectively. The decreased removal efficiency of phenol with an increase in temperature, demonstrates an exothermic process. The decrease in biosorption with the increase in temperature was owing to the weakening of the attractive force between the adsorbate and CSAC, and comparable due to the improvement of thermal energies of the adsorbate, therefore, production of the attractive forces between biosorbent and adsorbate is not strong sufficient to hold the adsorbed molecules at the active binding sites (Mukherjee et al. 2007). The increase in biosorption of cyanide with increase in temperature is maybe due to rise in active biosorption sites resulting from the internal bonds breaking at near the edge of the active sites of the biosorbent surface and shows an endothermic process (Dash et al. 2009). As the temperature of solution increase, the viscosity of solution start to decrease, and therefore, increase in the rate of diffusion of adsorbate inside the pores (Mukherjee et al. 2007; Stavropoulos et al. 2015; Dash et al. 2009b, c). Therefore, the optimum temperature was designated as $30{ }^{\circ} \mathrm{C}$ for both phenol and cyanide.

\section{Effect of initial concentration of phenol and cyanide}

The initial concentration of adsorbate offers a significant driving force to overcome all the mass transfer resistance of cyanide and phenol between the solid and aqueous phase. The biosorption of phenol and cyanide onto CSAC was calculated by changing the initial concentration at constant biosorbent dose, contact time, temperature and pH (Fig. 5a, b). It was established that the removal percentage of phenol was decreased from 99.64 to $76.39 \%$ as the initial concentration of phenol increased from 100 to $1000 \mathrm{mg} / \mathrm{L}$ and percentage removal of cyanide was decreased from 98.2 to $73.4 \%$ as the initial concentration of cyanide increased from 10 to $100 \mathrm{mg} / \mathrm{L}$. The high removal efficiency at lower concentrations may be owing to the existence of more available vacant sites on the biosorbent than the number of phenol and cyanide ions which exist in the solution. Though, at higher concentrations, the ions of phenol and cyanide are comparatively higher than the available vacant sites for biosorption.

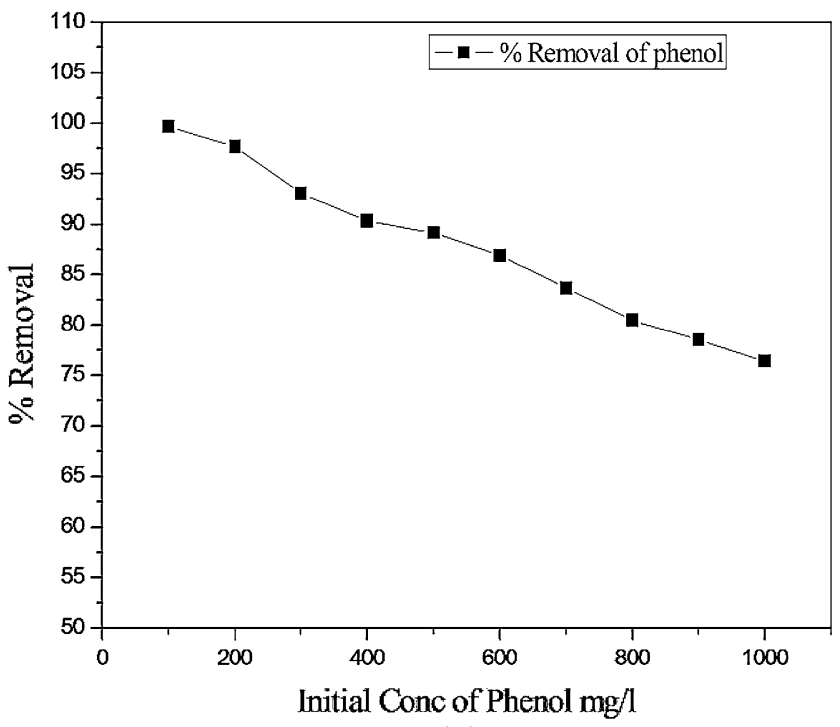

(a)

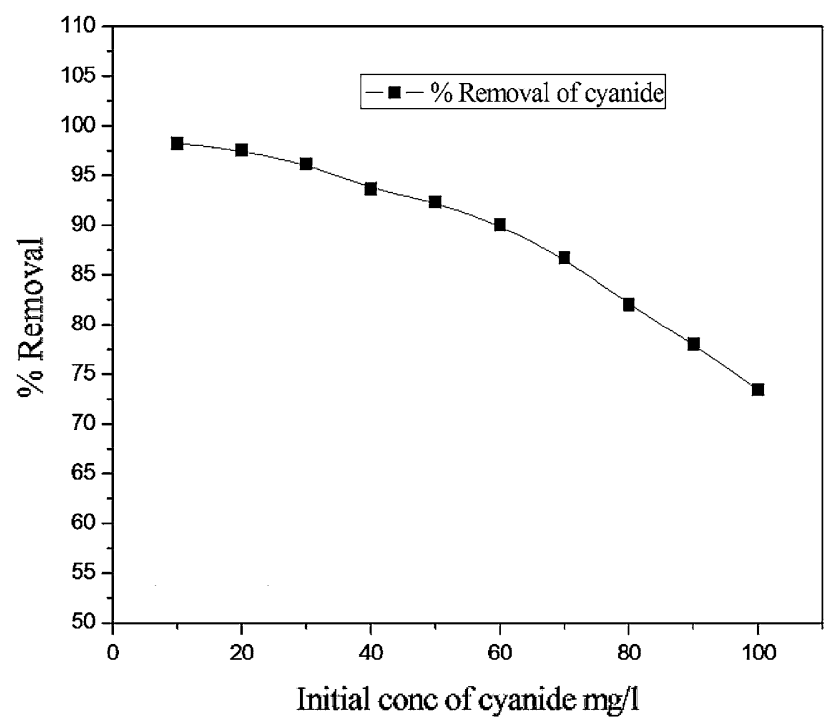

(b)

Fig. 5 a Effect of initial concentration of phenol on \% removal, b Effect of initial concentration of cyanide on \% removal (process conditions: biosorbent dosage of $30 \mathrm{~g} / \mathrm{L}, \mathrm{pH}$ of 8 , temperature $30{ }^{\circ} \mathrm{C}$ and contact time $50 \mathrm{~h}$ ) 


\section{Adsorption equilibrium isotherm study}

The modeling and processing of adsorption experimental data are essential for the process engineering (e.g., operation, optimization, design) of wastewater treatment schemes (Kumar et al. 2011). According to the literature, several monocomponent and binary component biosorption models can be employed to fit experimental biosorption data (Kumar et al. 2011).

\section{Monocomponent equilibrium isotherm}

The MPSD values of isotherm can be used to obtain the best fit model were listed in Table 2. Comparison of monocomponent isotherm models are given in Fig. 6a, b. From the table and figure, the best fitted isotherm models for phenol are evaluated in the order: (Freundlich $>$ Redlich-Peterson $>$ Fritz-Schlunder $>$ Toth $>$ Langmuir), and best fitted isotherm models for cyanide adsorption onto CSAC are in the order: (Toth $>$ Fritz-Schlunder $>$ Redlich-Peterson $>$ Freundlich $>$ Langmuir).

In this study, the value of $R_{\mathrm{L}}$ has been found less than 1 for both phenol and cyanide indicating that the biosorption of phenol and cyanide onto CSAC is very favorable under prevalent operating conditions. The Freundlich isotherm constant $n$ were, calculated to be more than unity for both phenol and cyanide representing that the biosorption of the phenol and cyanide onto the CSAC is favorable (Aksu and Akpinar 2008). However, the values of $Q_{0}$ for phenol were found to be more than that of cyanide which could be described on the basis of higher concentration of phenol in the binary solution.

\section{Binary component equilibrium isotherm}

For the binary component isotherm study, a binary component aqueous solution of phenol and cyanide was used and the simultaneous biosorption and bioaccumulation was studied at $30{ }^{\circ} \mathrm{C}$. It was noticed that percentage removal of both components decreased with increased initial concentration. Binary component isotherm study results demonstrate that for $500 \mathrm{mg} / \mathrm{L}$ concentration of phenol with the presence of $50 \mathrm{mg} / \mathrm{L}$ of cyanide, $Q_{\mathrm{ph}}$ was $14.85 \mathrm{mmol} \mathrm{g} / \mathrm{L}$. Similarly for $100 \mathrm{mg} / \mathrm{L}$ concentration of cyanide with the presence of $1000 \mathrm{mg} / \mathrm{L}$ of phenol, $Q_{\mathrm{ph}}$ was $25.46 \mathrm{mmol} \mathrm{g} /$ $\mathrm{L}$ for CSAC. It is observed that capacity of competitive biosorption is increased, which is due to fact that its dependence on the initial concentration of the pollutants, the surface structure of the biosorbents and the molecular structure of the competing adsorbate (Ren et al. 2007). Comparison of binary component isotherm models is given in Fig. 7a, b.

It is evident from Table 2 that extended Freundlich model indicate a better fit for experimental biosorption with low

Table 2 Monocomponent and binary component model parameters for simultaneous biosorption and bioaccumulation of phenol and cyanide onto CSAC

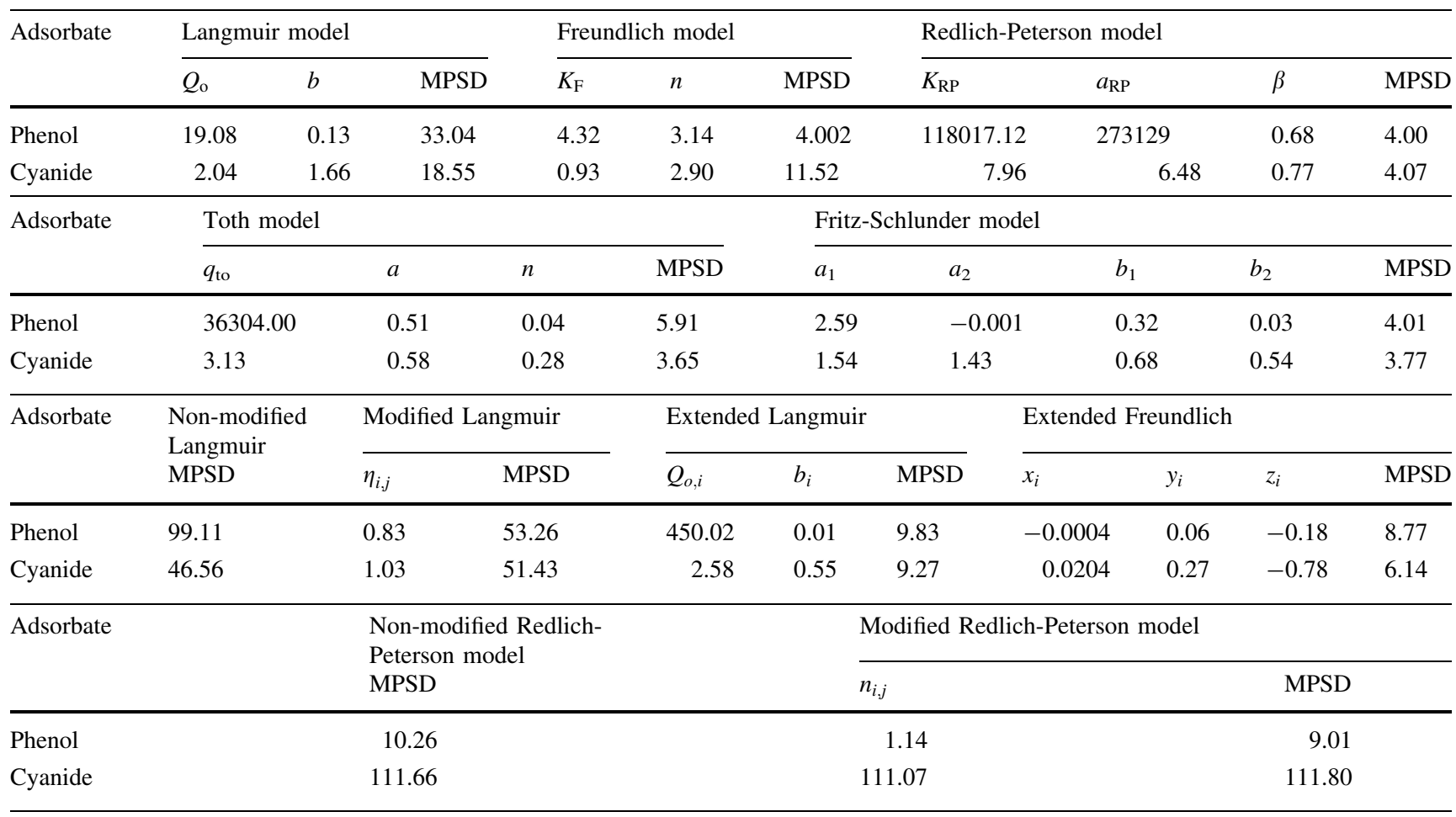




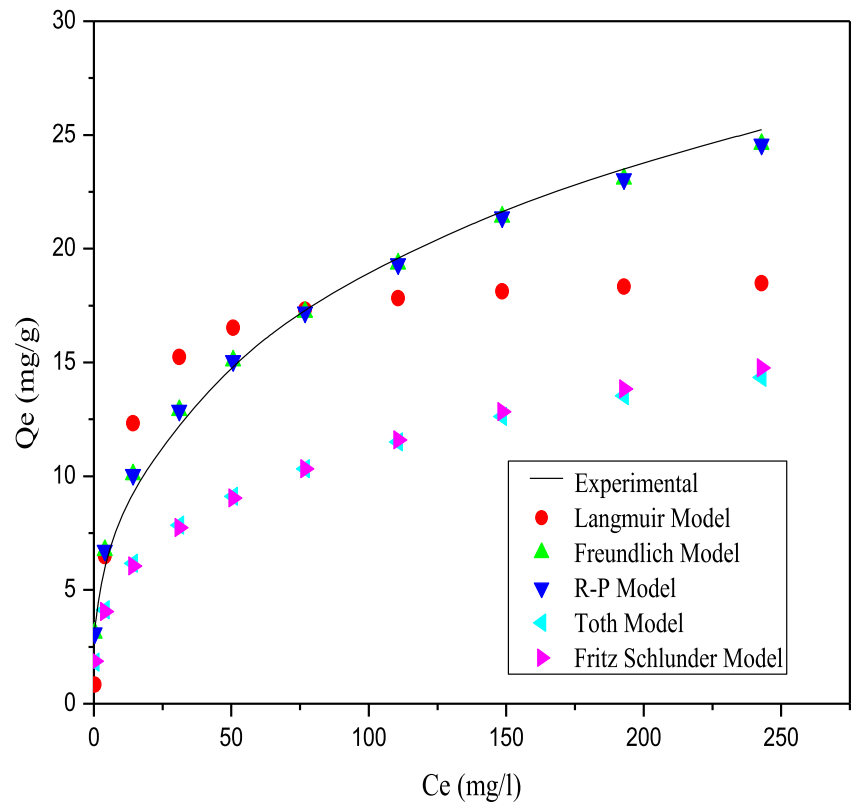

(a)

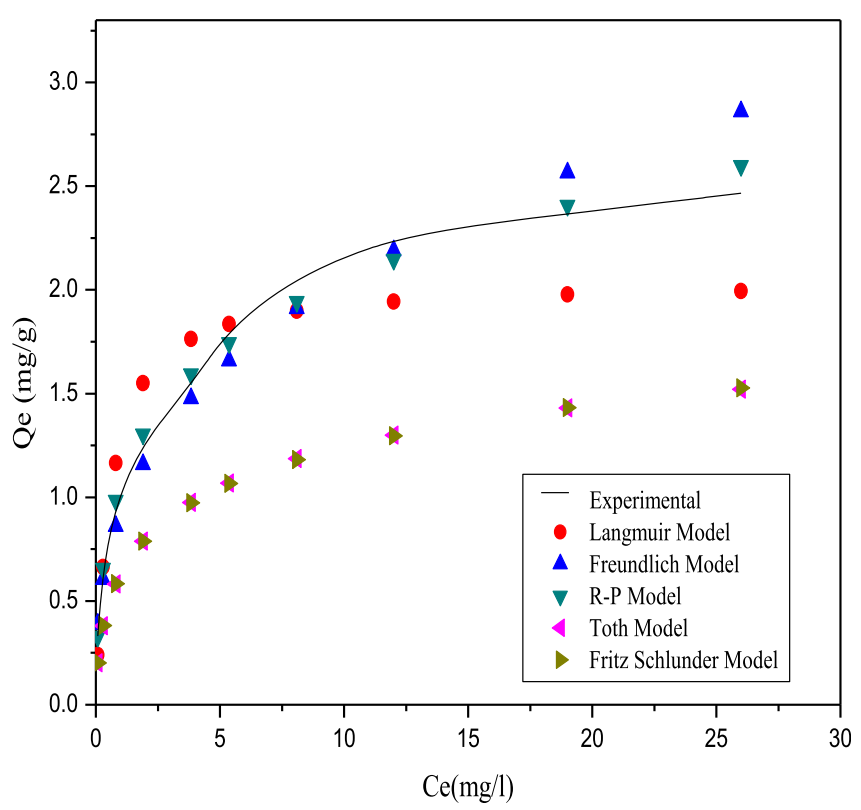

(a)

Fig. 6 a Comparison of monocomponent isotherm models for phenol, b comparison of monocomponent isotherm models for cyanide

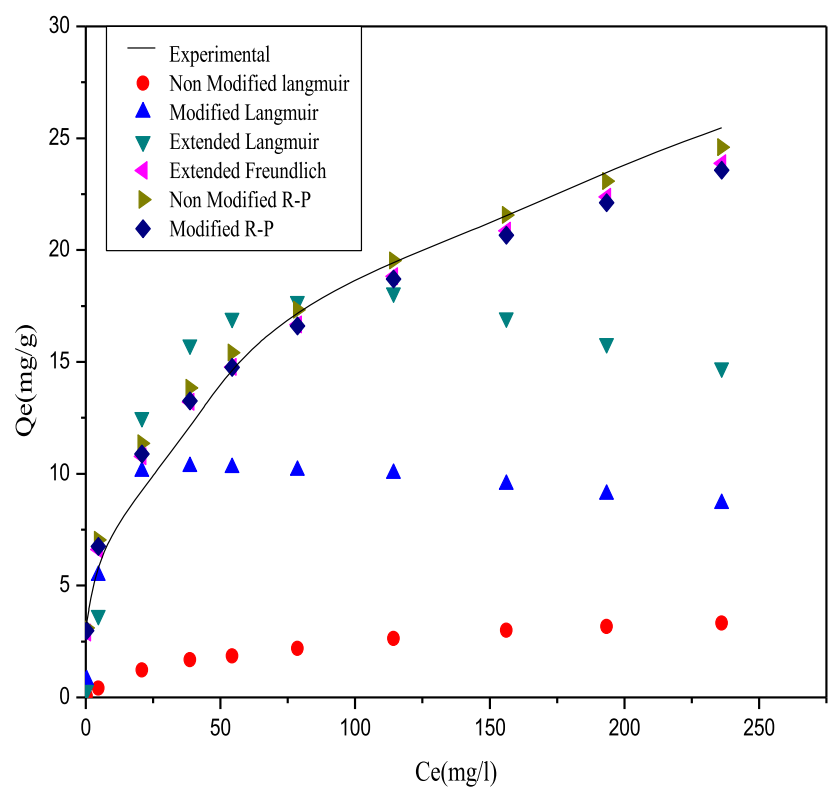

(a)

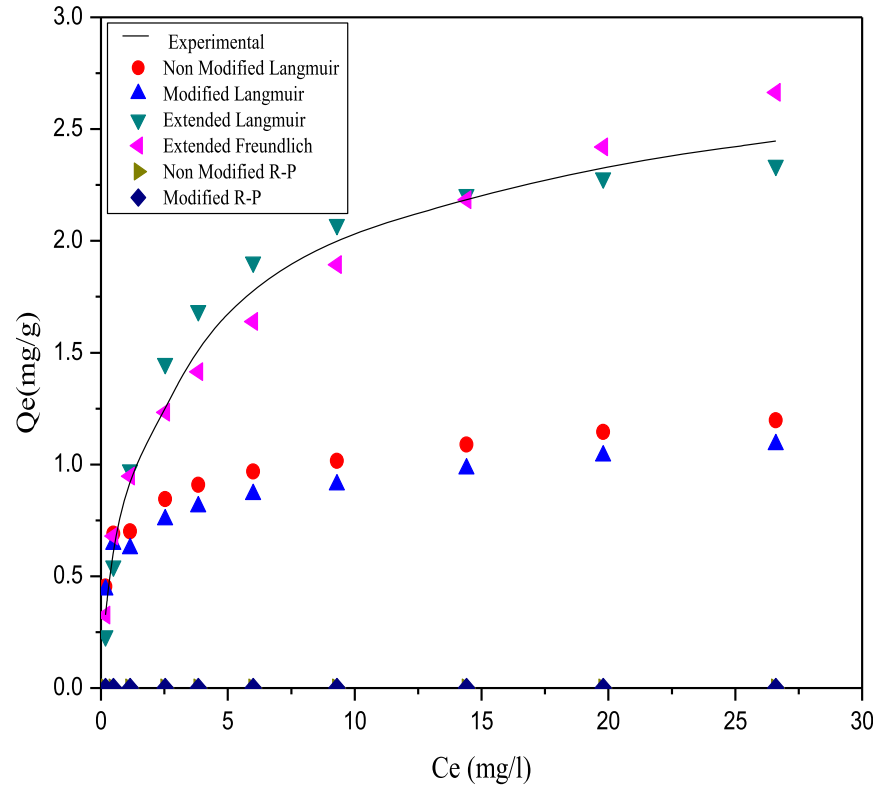

(b)

Fig. 7 a Comparison of binary component isotherm models for phenol, b comparison of binary component isotherm models for cyanide

MPSD values for phenol and cyanide. Biosorption of phenol followed the tendency of better fit models as: non-modified Langmuir $<$ modified Langmuir $<$ non-modified RedlichPeterson $<$ extended Langmuir $<$ modified Redlich-Peterson $<$ extended Freundlich, whereas biosorption of cyanide followed the trend: modified Redlich-Peterson $<$ non-modified $\quad$ Redlich-Peterson $<$ modified $\quad$ Langmuir $<$ non- modified Langmuir $<$ extended $\quad$ Langmuir $<$ extended Freundlich.

In this study, the ratio of capacities of adsorption process $\left(Q_{q, i}\right)$ for phenol and cyanide was calculated as 23.58 and 1.27, hence founding the fact that both phenol and cyanide show synergism effects. 
Table 3 Kinetic model parameters for simultaneous biosorption and bioaccumulation of phenol and cyanide onto CSAC

\begin{tabular}{|c|c|c|c|}
\hline Kinetic models & Parameters & Phenol & Cyanide \\
\hline \multirow{3}{*}{$\begin{array}{l}\text { Fractional power } \\
\text { model }\end{array}$} & $k_{\mathrm{fp}}$ & 0.9426 & 0.1527 \\
\hline & $v$ & 0.7418 & 0.6263 \\
\hline & MPSD & 1.7384 & 1.2814 \\
\hline \multirow[t]{3}{*}{ Pseudo first order } & $q_{\mathrm{e}}$ & 19.226 & 1.7059 \\
\hline & $k_{1}$ & 0.0336 & 0.0515 \\
\hline & MPSD & 1.365 & 1.3793 \\
\hline \multirow[t]{3}{*}{ Pseudo second order } & $q_{\mathrm{e}}$ & 30.531 & 2.4399 \\
\hline & $k_{2}$ & 0.0007 & 0.0161 \\
\hline & MPSD & 1.4101 & 1.2348 \\
\hline \multirow[t]{3}{*}{ Elovich model } & $a_{\mathrm{el}}$ & 1.2305 & 0.158 \\
\hline & $b_{\mathrm{el}}$ & 0.6678 & 1.215 \\
\hline & MPSD & 1.1291 & 1.1415 \\
\hline \multirow[t]{4}{*}{ Avrami model } & $q_{\mathrm{e}}$ & 19.225 & 1.7059 \\
\hline & $k_{\mathrm{av}}$ & 0.1526 & 0.2024 \\
\hline & $n_{\mathrm{av}}$ & 0.2201 & 0.2546 \\
\hline & MPSD & 1.365 & 1.3793 \\
\hline \multirow{4}{*}{$\begin{array}{l}\text { Modified second } \\
\text { order model }\end{array}$} & $q_{\mathrm{e}}$ & 34.808 & 2.8986 \\
\hline & $k_{1 \mathrm{~m}}$ & 0.0173 & 0.0267 \\
\hline & $b_{1 \mathrm{~m}}$ & 1.0095 & 1.0296 \\
\hline & MPSD & 1.2879 & 0.7972 \\
\hline \multirow{3}{*}{$\begin{array}{l}\text { Ritchie second order } \\
\text { model }\end{array}$} & $q_{\mathrm{e}}$ & 30.523 & 2.4399 \\
\hline & $k_{1 \mathrm{R}}$ & 0.0219 & 0.0394 \\
\hline & MPSD & 1.41 & 1.2348 \\
\hline \multirow{3}{*}{$\begin{array}{l}\text { Exponential kinetic } \\
\text { model }\end{array}$} & $q_{\mathrm{e}}$ & 23.489 & 1.9152 \\
\hline & $k_{\mathrm{ex}}$ & 0.0166 & 0.029 \\
\hline & MPSD & 1.4038 & 1.2363 \\
\hline \multirow{4}{*}{$\begin{array}{l}\text { Mixed first, second } \\
\text { order model }\end{array}$} & $q_{\mathrm{e}}$ & 28.797 & 2.2689 \\
\hline & $k_{\mathrm{m}}$ & 0.0027 & 0.0055 \\
\hline & $f_{2}$ & 0.8827 & 0.8699 \\
\hline & MPSD & 1.4096 & 1.2371 \\
\hline \multirow{5}{*}{$\begin{array}{l}\text { Fractal-like mixed } \\
\text { first, second order } \\
\text { model }\end{array}$} & $q_{\mathrm{e}}$ & 17.239 & 1.9153 \\
\hline & $f_{\text {eq }}$ & -20.773 & -14.53 \\
\hline & $k_{\mathrm{fm}}$ & 0.7742 & 0.8039 \\
\hline & $\alpha$ & 0.4862 & 0.4405 \\
\hline & MPSD & 0.9178 & 0.6903 \\
\hline \multirow{4}{*}{$\begin{array}{l}\text { Fractal-like first } \\
\text { order model }\end{array}$} & $q_{\mathrm{e}}$ & 21.146 & 2.3531 \\
\hline & $k_{\mathrm{ff}}$ & -0.0332 & -0.0527 \\
\hline & $a$ & 0.9537 & 0.8051 \\
\hline & MPSD & 1.3427 & 0.9397 \\
\hline \multirow{4}{*}{$\begin{array}{l}\text { Fractal-like second } \\
\text { order model }\end{array}$} & $q_{\mathrm{e}}$ & 33.843 & 3.793 \\
\hline & $k_{\mathrm{fs}}$ & 0.0006 & 0.0087 \\
\hline & $a$ & 0.9641 & 0.8125 \\
\hline & MPSD & 1.3992 & 0.9783 \\
\hline \multirow{4}{*}{$\begin{array}{l}\text { Fractal-like } \\
\quad \text { exponential model }\end{array}$} & $q_{\mathrm{e}}$ & 26.149 & 2.8511 \\
\hline & $k_{\text {fex }}$ & 0.0158 & 0.0255 \\
\hline & $a$ & 0.9614 & 0.8187 \\
\hline & MPSD & 1.3949 & 0.9759 \\
\hline
\end{tabular}

Table 3 continued

\begin{tabular}{llcc}
\hline Kinetic models & Parameters & Phenol & Cyanide \\
\hline Brouser-Weron- & $q_{\mathrm{e}}$ & 17.524 & 2.0091 \\
Sototlongo model & $t_{\mathrm{bws}, \alpha}$ & 20.104 & 21.895 \\
& $n_{\mathrm{bws}}$ & 2.0871 & 2.0968 \\
& $a$ & 1.8118 & 1.4651 \\
& MPSD & 0.4532 & 0.5475 \\
\hline
\end{tabular}

\section{Kinetic study}

Kinetic data of adsorbate uptake is essential to know the optimum operating conditions for batch process. A nonlinear regression analysis technique was used to solve the adsorption kinetic models. Table 3 demonstrates the values of kinetic model constants for the removal of phenol and cyanide by S. odorifera (MTCC 5700) immobilized on the surface of CSAC. High error values recommending that these models (fractional power, pseudo first order, Avrami and exponential) are not suitable for both phenol and cyanide. The best fit model was determined on the basis of error functions MPSD. On the basis of the lowest error function values MPSD, the perfect fitting of the experimental results was attained using Brouser-Weron-Sototlongo model (Fig. 8a, b) for both phenol and cyanide among all the tried kinetic models.

On the basis of the lowest error values MPSD, BrouserWeron-Sototlongo kinetic model indicates better fit with the experimental data as compared to the other models. The better fit of Brouser-Weron-Sototlongo kinetic model indicates that the removal of both phenol and cyanide onto S. odorifera (MTCC 5700) immobilized on the surface of CSAC followed chemisorption interactions type, revealing that the rate controlling step might be chemical adsorption comprising valency forces over exchange or distribution of electrons between phenol and cyanide anions and $S$. odorifera MTCC 5700 immobilized on to CSAC. Furthermore, the Brouser-Weron-Sototlongo kinetic model states additional notable data which is the time important to adsorb half the maximum amount $\left(t_{\mathrm{bws}, \alpha}\right)$. Brouser-WeronSototlongo kinetic model has a good fitting performance; it states such quality data (i.e., adsorption capacity close to experimental data, qe(BWS), and the time of half reaction $\left(t_{\mathrm{bws}, \alpha}\right)$ which are very useful for an industrial treatment design (Ncibi et al. 2014). For Fractal-like models, such as Fractal-like pseudo first order, Fractal-like pseudo second order, Fractal-like exponential, Fractal-like mixed first, second order) the rate coefficient for adsorption is measured as a function of time using the Fractal-like idea. One of the possible physical meanings of Fractal-like kinetics was that adsorption of phenol and cyanide happened at solid/solution edge. In this methodology, it was indicated 


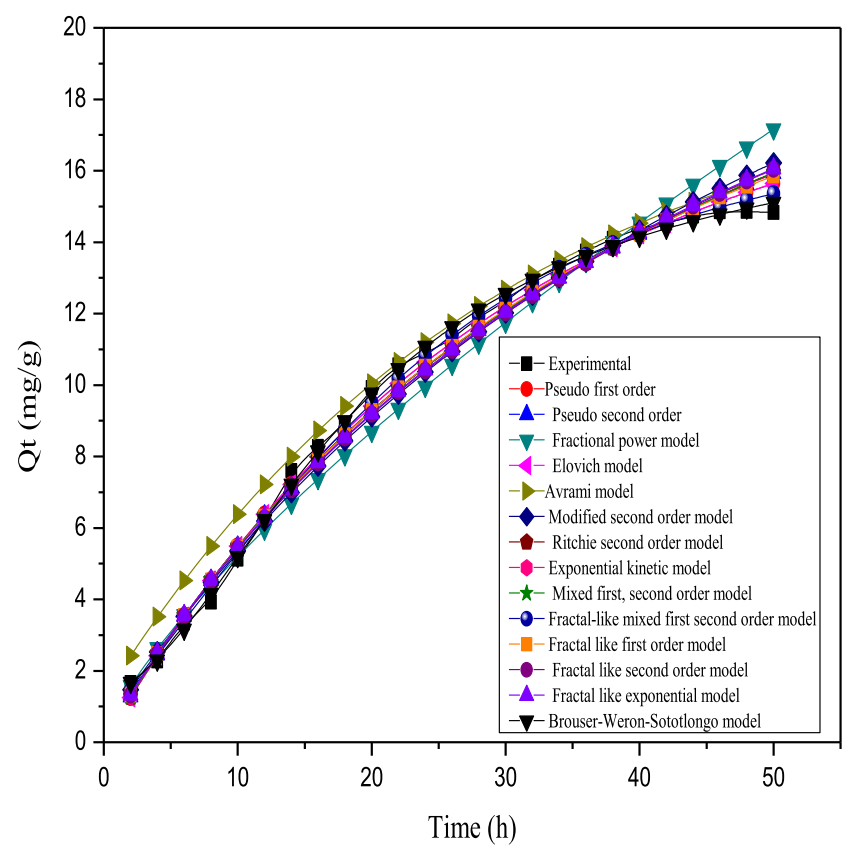

(a)

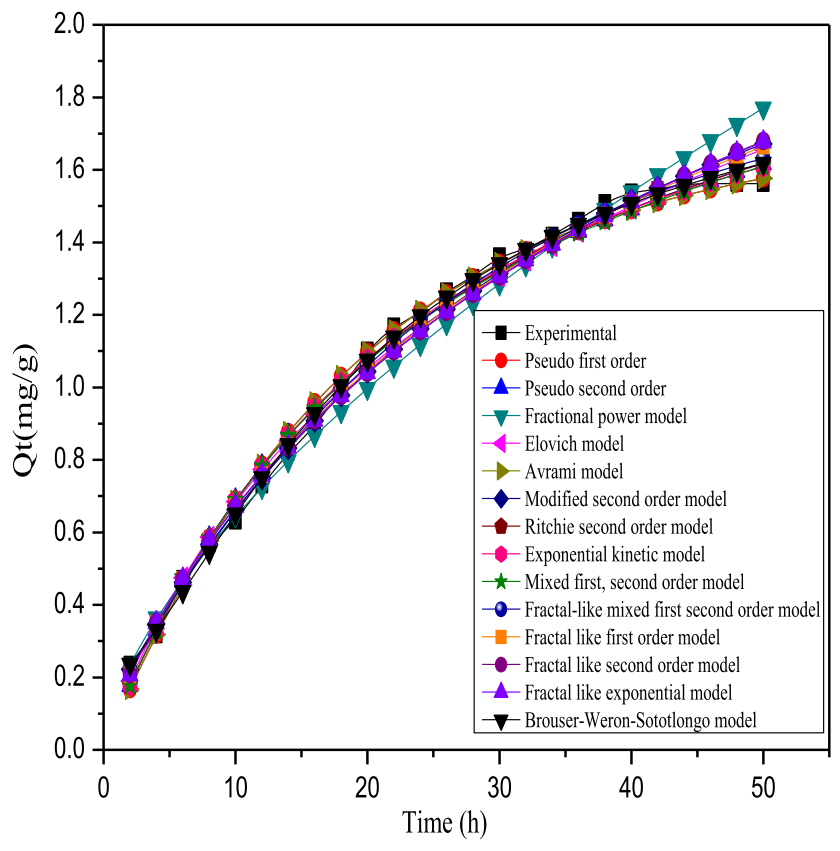

(b)

Fig. 8 a Comparison of kinetic models for phenol, b comparison of kinetic models for cyanide

that by passing time, several paths for phenol and cyanide adsorption on adsorbent surface seems. The error values MPSD for Fractal-like mixed first, second order model and Brouser-Weron-Sototlongo kinetic model was better than that other kinetic models for phenol and cyanide. Fractallike mixed first, second order kinetic model representing the rate of adsorption was dependent on the initial concentration of adsorbate in solution and rate of agitation. However, the Brouser-Weron-Sototlongo kinetic model revealed the complex mechanism of removal process. Figure $8 \mathrm{a}$ and $\mathrm{b}$ demonstrates the comparison of kinetic models for phenol and cyanide removal, respectively.

\section{Conclusions}

Batch studies for the removal of phenol and cyanide from the binary component aqueous solution have been carried out using activated carbon acquired from coconut shell with immobilization of bacterium $S$. odorifera (MTCC 5700). Optimum conditions for simultaneous biosorption and bioaccumulation of phenol and cyanide were accomplished at CSAC dosage of $30 \mathrm{~g} / \mathrm{L}, \mathrm{pH}$ of 8 , and temperature $30{ }^{\circ} \mathrm{C}$ with an initial concentration $500 \mathrm{mg} / \mathrm{L}$ of phenol and $50 \mathrm{mg} / \mathrm{L}$ of cyanide. Under the optimal conditions, maximum phenol and cyanide removal efficiencies were acquired as 71.36 and $88.40 \%$ from simultaneous biosorption and bioaccumulation process. In conclusion, a binary component system was found better than monocomponent biosorption system for the simultaneous elimination of phenol and cyanide using $S$. odorifera (MTCC 5700) immobilized onto CSAC biosorbent surface. In a binary component system among six multicomponent isotherms, extended Freundlich model indicate a better fit for both phenol and cyanide. Therefore, a synergism effects were exhibited for both phenol and cyanide, in binary component system. Among different kinetic models used in this study, BrouserWeron-Sototlongo kinetic model as well as Fractal-like mixed first second order kinetic models for phenol and cyanide found appropriate to calculate the adsorption kinetic onto CSAC. S. odorifera (MTCC 5700) immobilized on the surface of CSAC can be used as a capable biosorbent for the removal of both phenol and cyanide from wastewater.

Acknowledgments The authors greatly acknowledge and appreciate the Ministry of Human Resource and Development, Government of India (MHRD, New Delhi) for providing financial support, and the facilities provided by IIT Roorkee, Roorkee.

Open Access This article is distributed under the terms of the Creative Commons Attribution 4.0 International License (http:// creativecommons.org/licenses/by/4.0/), which permits unrestricted use, distribution, and reproduction in any medium, provided you give appropriate credit to the original author(s) and the source, provide a link to the Creative Commons license, and indicate if changes were made. 


\section{References}

Agarwal B, Balomajumder C (2012) Coke waste water: a source of phenol and cyanide assimilating bacteria. J Sci Tech Maneg $5(1): 33-38$

Agarwal B, Balomajumder C (2013) Simultaneous adsorption and biodegradation of phenol and cyanide in multicomponent system. Inter J Environ Eng Manage 4:233-238

Agarwal B, Balomajumder C, Thakur PK (2013) Simultaneous coadsorptive removal of phenol and cyanide from binary solution using granular activated carbon. Chem Eng J 228:655-664

Akcil A (2003) Destruction of cyanide in gold mill effluents: biological versus chemical treatments. Biotechnol Adv 21:501-511

Aksu Z, Akpinar D (2008) Simultaneous adsorption of phenol and chromium (VI) from binary mixtures onto powdered activated carbon. J Environ Sci Health 3:379-405

Amudaa OS, Giwa AA, Bello IA (2007) Removal of heavy metal from industrial wastewater using modified activated coconut shell carbon. Biochem Eng J 36:174-181

APHA (1998) Standard methods for examination of water and wastewater, 20th edn. American Public Health Association, Washington, DC, USA

ATSDR (2006) Agency for toxic substances and disease registry, toxicological profile for cyanide, US, Department of Health and Human Services, Public Health Statement

ATSDR (2008) Agency for toxic substances and disease registry, toxicological profile for Phenol, US, Department of Health and Human Services, Public Health Service

Busca G, Berardinelli S, Resini C, Arrighi L (2008) Technologies for the removal of phenol from fluid streams: a short review of recent developments. J Hazard Mater 160:265-288

Carvalho MF, Duque AF, Goncalves IC, Castro PML (2007) Adsorption of fluorobenzene onto granular activated carbon: isotherm and bioavailability studies. Bioresour Technol 98:3424-3430

Daffalla SB, Mukhtar HS, Shaharun M (2013) Removal of phenol from aqueous solutions using rice husk ash. Casp J Appl Sci Res 2:36-49

Dash RR, Majumder CB, Kumar A (2008) Treatment of metal cyanide bearing wastewater by simultaneous adsorption and biodegradation (SAB). J Hazard Mater 152:387-396

Dash RR, Gaur A, Balomajumder C (2009a) Cyanide in industrial wastewaters and its removal: a review on biotreatment. J Hazard Mater 163:1-11

Dash RR, Balomajumdar C, Kumar A (2009b) Removal of cyanide from water and wastewater using granular activated carbon. Chem Eng J 146(1):408-413

Dash RR, Balomajumdar C, Kumar A (2009c) Removal of metal cyanides from aqueous solutions by suspended and immobilized cells of Rhizopus oryzae (MTCC 2541). Eng Life Sci J 9(1):53-59

Dash RR, Balomajumdar C, Kumar A (2009d) Treatment of cyanide bearing water/wastewater by plain and biological activated carbon. J Ind Engg Chem Res 48(7):3619-3627

Dash RR, Dash RR, Balomajumdar C (2014) Treatment of cyanide bearing effluents by adsorption, biodegradation and combined processes: effect of process parameters. Desalin Water Treat 52:3355-3366

Deveci H, Yazıc1 EY, Alp I, Uslu T (2006) Removal of cyanide from aqueous solutions by plain and metal-impregnated granular activated carbons. Int J Min Process 79:198-208

Doney SC (2010) The growing human footprint on coastal and openocean biogeochemistry. Science 328:1512-1516

Haerifar M, Azizian S (2013) An exponential kinetic model for adsorption at solid/solution interface. Chem Eng J 215-216:65-71
Kilic M, Varol EA, Putun AE (2011) Adsorptive removal of phenol from aqueous solutions on activated carbon prepared from tobacco residues: equilibrium, kinetics and thermodynamics. J Hazard Mater 189:397-403

Kim MY, Park D, Jeon CO, Lee SD, Park MJ (2008) Effect of HRT on biological pre denitrification process for the simultaneous removal of toxic pollutants form cokes wastewater. Bioresour Technol 99:8824-8832

Kirubakaran CJ, Krishnaiah K, Seshadri SK (1991) Experimental study of the production of activated carbon from coconut shells in a fluidized bed reactor. Ind Eng Chem Res 30:2411-2416

Kujawski W, Warszawski A, Ratajczak W, Porebski T, Capala W (2004) Removal of phenol from wastewater by different separation techniques. Desal 163:287-296

Kumar S, Zafar M, Prajapati JK, Kumar S, Kannepalli S (2011) Modeling studies on simultaneous adsorption of phenol and resorcinol onto granular activated carbon from simulated aqueous solution. J Hazard Mater 185:287-294

Lin S, Juang R (2009) Adsorption of phenol and its derivatives from water using synthetic resins and low-cost natural adsorbents: a review. J Environ Manag 90:1336-1349

Liu J, Baozhen W, Li W, Chengji J, Cao X, Wang LM (1996) Removal of nitrogen from coal gasification and coke plant wastewater in anoxic-aerobic submerged biofilm-activated sludge (SBF-AS) hybrid system. Water Sci Technol 34:17-24

Lu D, Zhang Y, Niu S, Wang L, Lin S, Wang C et al (2012) Study of phenol biodegradation using Bacillus amyloliquefaciens strain WJDB-1 immobilized in alginate-chitosan-alginate (ACA) microcapsules by electrochemical method. Biotechnol 23:209-219

Michalak I, Chojnacka K, Witek-Krowiak A (2013) State of the art for the biosorption process-a review. Appl Biochem Biotechnol 170:1389-1416

Mondal P, Majumder CB, Mohanty B (2008) Effects of adsorbent dose, its particle size and initial arsenic concentration on the removal of arsenic, iron and manganese from simulated ground water by $\mathrm{Fe}^{3+}$ impregnated activated carbon. J Hazard Mater 150:695-702

Moussavi G, Khosravi R (2010) Removal of cyanide from wastewater by adsorption onto pistachio hull wastes: parametric experiments, kinetics and equilibrium analysis. J Hazard Mater 183:724-730

Mukherjee S, Kumar S, Misra AK, Fan M (2007) Removal of phenols from water environment by activated carbon, bagasse ash and wood charcoal. Chem Eng J 129:133-142

Ncibi MC, Ranguin R, Pintor MJ, Jeanne-Rose V, Sillanpää M, Gaspard S (2014) Preparation and characterization of chemically activated carbons derived from Mediterranean Posidonia oceanica (L.) fibres. J Anal Appl Pyrolysis 109:205-214

Panagou EZ, Kodogiannis VS (2009) Application of neural networks as a nonlinear modelling technique in food mycology. Expert Syst Appl 36:121-131

Prieto M, Hidalgo AJ, Serra L, Llama MJ (2002) Degradation of phenol by Rhodococcus erythropolis UPV-1 immobilized on Biolite in a packed-bed reactor. J Biotechnol 97:1-11

Ren J, Huo CF, Wen XD, Cao Z, Wang JG, Li YW et al (2007) Adsorption of $\mathrm{NO}, \mathrm{NO}_{2}$, pyridine and pyrrole on $\alpha-\mathrm{M}_{2} \mathrm{C}(0001)$. Surf Sci 601:1599-1607

Reynel-Avila HE, Mendoza-Castillo DI, Hernández-Montoya V, Bonilla-Petriciolet A (2011) Multicomponent removal of heavy metals from aqueous solution using low-cost sorbents. In: Antizar-Ladislao B, Sheikholeslami R (eds) Water production and wastewaters treatment, vol 1. Nova Science Publisher, New York, pp 69-99

Sawalha MF, Peralta-Videa JR, Romero-Gonzales J, Gardea-Torresdey JL (2006) Biosorption of $\mathrm{Cd}(\mathrm{II}), \mathrm{Cr}(\mathrm{III})$, and $\mathrm{Cr}(\mathrm{IV})$ by 
saltbush (Atriplex canescens) biomass: thermodynamic and isotherm studies. J Colloid Interface Sci 300:100-104

Silva M, Fernandes A, Mendes A, Manaia CM, Nunes OC (2004) Preliminary feasibility study for the use of an adsorption/ bioregeneration system for molinate removal from effluents. Water Res 38:2677-2684

Singh N, Agarwal B, Balomajumder C (2016) Simultaneous treatment of phenol and cyanide containing aqueous solution by adsorption, biotreatment and simultaneous adsorption and biotreatment (SAB) process. J Environ Chem Eng 4:564-575

Sodeinde OA (2012) Preparation of a locally produced activated carbon from coconut shells and its use in reducing hexamine cobalt (III). Inter J Chem Eng and App 3:67-71
Srihari V, Das A (2008) The kinetic and thermodynamic studies of phenol-sorption onto three agro-based carbons. Desal 225:220-234

Stavropoulos GG, Skodras GS, Papadimitriou KG (2015) Effect of solution chemistry on cyanide adsorption in activated carbon. Appl Therm Eng 74:182-185

Su W, Zhou L, Zhou YP (2003) Preparation of microporous activated carbon from coconut shells without activating agents. Carbon 41:861-863

Vedula RK, Balomajumder C (2011) Simultaneous adsorptive removal of cyanide and phenol from industrial wastewater: optimization of process parameters. Res J Chem Sci 4:30-39 